\title{
DEVELOPING LANGUAGE COMPETENCE FOR TOURISM STUDENTS AND EMPLOYEES IN A BLENDED LEARNING LANGUAGE COURSE
}

\author{
Ineta Luka \\ Turiba University, Latvia
}

\begin{abstract}
The paper presents the main findings of the second stage of Erasmus + project „Key Skills for European Union Hotel Staff" (2014-2016) - the online course designed for A2/B1 level of language competence in 12 European languages and B2/C1 English language course to promote tourism students' and employees' language competence and raise their intercultural awareness. It analyses pedagogical, linguistic and field professional literature on course creation and presents the conducted evaluation research containing formative evaluation from three perspectives - provider (document review), recipient (a focus group interview with 14 learners) and wider community (a focus group interview with 7 hospitality industry managers and a survey of 21 language teachers from six countries) to identify the initiative's consequences and opportunities for modification and improvement. The strengths and weaknesses of the course have been identified and suggestions on how the process could be made more efficient/effective for the organisation, the end users and the community have been provided.
\end{abstract}

Keywords: blended learning, curriculum, e-learning, global competences, language competence, online learning.

\section{Introduction}

Over the past forty years tourism has grown substantially and has become one of the largest global economic sectors in the world attaining social and environmental significance (Scott \& Gössling, 2015). Consequently it has led to the necessity for qualified hospitality industry staff worldwide. According to Beesley and Davidson (2013) literacy and numeracy are fundamental requirements, and, considering the specifics of hospitality industry, a range of industry specific employability skills related with serving the customers are significant. These skills should lie at the core of any curriculum in service industries.

As numerous studies show, languages have been and will remain especially significant in hospitality industry (Millar \& Park, 2013). Moreover, the role of languages has significantly increased in the last couple of years. This has also been caused by the current situation in Europe which can be characterised by „unprecedented movement and change” (King et al., 2011, 7). The increasing 
tourism flows, mobility for study and professional reasons as well as global migration processes have placed Europe in a previously unknown situation in which multilingualism is becoming not a desired state but a vital necessity.

Communication is no longer regarded as an aim but is considered as a tool for participating in socially meaningful activities (Kaya, 2015) in everyday and professional settings. This new situation consequently leads to a change in language teaching models as well. The contexts of language use are always somehow multilingual and interlocutors have to demonstrate their linguistic diversity in coping with the situation in practice. Consequently, a language learner's goal is to develop plurilingual language competence for operating in a multilingual environment. English plays a significant role as a medium in this process as plurilingualism may be supported "through the vehicle of English, whether as a language through which other languages can be learned or [..] simply because the existence of English as a lingua franca (and language of academic discourse) facilitates exchange and international recruitment" (King et al., 2011, 20). Therefore, English is often used as a medium in other language learning courses for international audiences and it is a means of passing information and the language applied for managing different online learning platforms, including the one developed in the current project.

The object of the research is the evaluation of the blended learning language course created for tourism students and professionals. The purpose of the study is to analyze the language learning course designed (content, methodology, activities/tasks, online learning platform and mobile application created) in three perspectives - provider, recipient and wider community perspective and introduce the changes required to create a course that would foster the development of tourism specialists' employability skills applying an integrated language learning approach. Such a course would enable hospitality industry employees to ease transitions to working life more effectively and have access to opportunities to develop their employability skills (Learning while Working, 2011), operate successfully in new multilingual everyday and professional contexts as well as engage in self-managed lifelong employability.

\section{Theoretical Framework}

Designing of any language learning course starts with a curriculum design based on the analysis of pedagogical, linguistic, field professional literature and conducted needs analysis comprising all stakeholders - learners, teachers, industry. Therefore, by applying effective language learning theories, curricula perspectives, different course formats, language teaching/learning theories and essential industry competences have been analysed in this research in order to 
create an innovative language learning course that corresponds to the current and future industry needs.

\section{Curricula Perspectives}

"The development and implementation of a curriculum operates at various levels of the education system. These levels can be described at the international (SUPRA), national/regional (MACRO), school (MESO), class, teaching group or teacher (MICRO) and even individual (NANO) level. The levels interact, and effective curriculum planning must allow for all of them." (Bracco et al., 2015b, 101) Concerning language curricula the SUPRA level comprises international reference documents, such as the Common European Framework of Reference for Languages (CEFR, 2001), the MACRO level involves study plans, syllabus, strategic specific aims, training standards, etc. The MESO level means adjustment of the school curriculum or study plan to match the specific profile of a school, as well as developments in partnership with businesses. The MICRO level comprises the definite course, textbooks and resources used and the NANO level - learners' individual learning experience in the lifelong learning context (Beacco et al., 2015a).

Although the current project involves six EU countries and comprises language learning modules created in 12 languages considering CEFR language levels and CEFR competence descriptors, its curriculum cannot be described at the SUPRA level as it does not impact international language learning policies. The curriculum compiled takes into consideration the results of needs analyses carried out in five project countries at the MACRO, MESO and MICRO level (cf. Luka, 2015). The MACRO level of the current curriculum is also associated with definite occupation standards and requirements in force in each partner country designed for hospitality industry employees. As the language learning course has been designed considering the specific needs of the partners' educational institutions and the modules will be incorporated in their regular language studies, the curriculum can be characterised at the MESO and MICRO level. Furthermore, the course is intended to be an online learning course which can also be used in a blended learning form and each learner can adapt it to their own learning needs. Therefore the curriculum can also be described at the NANO level.

\section{Blended Learning}

A curriculum may be implemented in several forms. Evaluating the needs of the target audience, a choice has to be made between traditional learning, elearning and blended learning. As tourism industry is a dynamic industry the 
course has to be flexible. Therefore the best option seems to be an open education course.

"Open education is defined as the learning experience that gives the learner a degree of flexibility in the choice of what (topics), where (place), when (pace) and how (method) to learn/study" (Muñoz et al., 2013, 172). It is evident that the use of ICT, mobile technologies and other technologies in a form of online learning, e-learning, m-learning, U-learning foster open education and provides opportunities of having an access to learning at any place and any time, including workplace.

Massive changes have taken place in the field of online learning since its origin in the mid1970s (Mejia \& Phelan, 2014, 343) leading to a paradigm shift in teaching/learning that has "resulted in the emergence of a new educational model" (ibid) which is now known as blended learning. Some authors (Labbas \& Shaban, 2013) call it even a new era in education.

Literature review shows that several terms are used to denote the same phenomenon: hybrid learning, mixed learning, b-learning, blended learning; and it can be applied to a broad range of teaching/learning situations (Olejarczuk, 2014). However, the most popular term is blended learning. Although both elearning and blended learning comprise online learning, it is not exactly the same.

Similarities and differences can be categorised into six groups: 1) place; 2) communication with students; 3) time; 4) materials and resources; 5) participation in classes; 6) feedback. Apart from an e-learning platform and Web 2.0 tools, blended learning is implemented also in a classroom setting. Although communication with students in e-learning is not limited there are no classroom meetings. Blending learning on the other hand has both indirect and direct communication with limited classroom meetings and unlimited online meetings. Regarding materials and resources, in blended learning alongside with e-learning resources, traditional course books are used as well. While online participation is characteristic to e-learning, both, face-to-face and online participation are part of blended learning. Regarding feedback, in blended learning it is direct, oral, immediate, real time, written, delayed (ibid, 2014). Blended learning has certain advantages over traditional and e-learning. The advantages over e-learning include better catering for individual needs, more student guidance. The advantages over traditional learning are greater flexibility, the extension of materials and learning scenarios outside the classroom, no problems encountered in classes with high numbers of students, different language proficiency levels and communication problems caused by using mother tongue in a language class (Bueno-Alastuey \& López Pérez, 2014).

Nowadays, blended learning has become an integral part of the learning process. It is incorporated in university studies, vocational education and non- 
formal education. However, blended learning course designers have to consider such issues as pedagogical approaches to teaching/learning, technological aspects, the requirements of specific groups etc. It means "much more than converting the content of an existing face-to-face course or activity into a selected online learning platform" (Wong et al., 2013, 252). The course may be considered as a blended learning course if computer (technology) assisted learning constitutes from 30 to $79 \%$ of the whole course content implementation. Such a course also typically uses online discussions and has some face-to-face meetings. In contrast, in a purely online course most material ( $80 \%$ and more) is delivered online and it has no face-to-face meetings (Allen et al., 2007). A wide spectrum of blending opportunities - from online learning used only for homework to the courses providing full integration of computer assisted language learning with online activities and technologies complementing face-to-face tasks, exist (Bueno-Alastuey \& López Pérez, 2014). When designing an online and/or blended learning course it is important to choose appropriate tools to foster learners' motivation and develop language competence. A good tool "allows faculty and students to do what they do best, as easily and efficiently as possible" to accomplish the task (Amemado, 2014, 26).

Finally, as stressed by Kaya (2015), another advantage of blended learning is the integration of virtual learning platforms and applying other technology in language learning which corresponds to constructivism learning theory and creates optimum learning conditions and fosters student-centred learning.

All learning, including language learning, occurs in social interaction (Kim, 2014). This assumption is also at the core of constructivism theory, according to which learning takes place in interaction with people in a definite environment and people actively construct their own knowledge which they apply in practice. Therefore, constructivist learning theories are dominant in language learning.

Constructivists of second language acquisition consider that supportive language learning environment facilitates learners' discourse management and encourages their output of the target language. In online learning, technologies help maintaining social interactions among diverse learners (Hsu, 2013) thus stimulating language learners to construct their own learning. This has also been taken into consideration when designing the modules of the current course. Another aspect considered is the global character of contemporary education in which a growing emphasis is laid on employability skills, social interaction, learning and thinking, communication, foreign languages and cross-cultural understanding. 
Ineta Luka. Developing Language Competence for Tourism Students and Employees in a Blended Learning Language Course

\section{Global competences}

Languages, especially Languages for Special Purposes (LSP), have a unique role in any curriculum, serving also as a means to acquire subjectspecific competences. This can be formulated as the main goal of LSP courses in tertiary and vocational education curricula. According to Beacco et al. (2015b) language competences involved in subject learning contribute to processing and acquiring subject knowledge, negotiating the meanings of new knowledge, reflecting on the material learnt, applying the knowledge gained to other contexts and generalizing the acquired procedural knowledge and skills. This is attained through listening and reading activities and then consolidated by writing and speaking activities.

In the globalised professional world strategic competencies are very significant. Concerning foreign language, "analytical/thinking skills and the ability to deal with and process authentic materials" are very important (Rüschoff, 2011, 29). Recently, the term global competences has been used in connection with languages and cultures to denote competences essential to operate successfully now and in the future in multilingual and multicultural professional environments.

Global competences are competences which activate knowledge, skills and attitudes through reflection and action and that are valid for all languages and cultures and at the same time concern the relationships between languages and between cultures. Scholars have formulated seven global competences essential for a language curriculum: 1) competence in managing linguistic and cultural communication in a context of otherness, 2) competence in the construction and broadening of a plural linguistic and cultural repertoire, 3) competence of decentring, 4) competence in making sense of unfamiliar linguistic and/or cultural features, 5) competence of distancing, 6) competence in critical analysis of the (communicative and/or learning) situation and activities one is involved in and 7) competence in recognising the "other" and "otherness" (Candelier et al., 2012).

Needless to say, the emphasis laid on tolerance, recognising other cultures and languages, communication using appropriate cultural and language nuances is significant in tourism and hospitality industry, as these employees meet people from different cultures, religions and ethnicities on daily basis, both in serving their customers and working with international teammates in creating a tourism product.

Sisson and Adams (2013) have reviewed literature dealing with essential competences in Hospitality Management studies in the period from 1994 to 2011. Their findings indicate that in most studies communication and language competences are found paramount. The most frequently mentioned competences 
and skills are: listening as the most important communication skill for career advancement; communication and interpersonal communication for career success; effective listening and verbal and written communication skills necessary for good customer care and gaining qualitative tourism education. A set of hard competencies (13), soft competencies (16) and mixed competencies (4) for successful operation in the industry has been defined. A range of these competencies is connected with communication, for example, presentation skills, managing staff meetings, negotiating staff meetings and others. Moreover, among the 16 soft competencies written communication skills are emphasised as well.

The following competences are developed in traditional foreign language learning: generic competences, such as, collaboration, team working, empathy, tolerance, positive attitude to work and commitment, adaptability; intercultural competences, including knowledge of cultural differences and peculiarities and language awareness; linguistic competence and discourse competence. Frendo (2005) and Maican (2014) argue that linguistic competence focuses on the basic elements of a language - phonology, grammar and vocabulary. Discourse competence, in turn, situates language in use, including language use for professional communication. Discourse competence encompasses all the four language skills - listening, speaking, reading and writing.

\section{Language Learning Tasks for LSP Blended Learning Course}

Certain factors have to be taken into consideration when creating teaching/learning materials for LSP courses: 1) topic and specialty, 2) learners' situation, 3) general and specific proficiency in the language of study at entry and exit levels, 4) students' previous educational and cultural experiences, 5 ) types and skills to be developed (whether reading or writing or speaking or listening), 6) expected outcomes of learning goals (Laborda, 2011). Moreover, "LSP materials should have rich input and include the language structures and content information to make tasks as realistic for the learners' language goals as possible" (ibid, 103).

Thus it is important to choose authentic texts topical for the industry bearing in mind that another function of an LSP course is to educate its learners in the field, provide information useful for their professional activity. Selecting adequate texts for reading and listening tasks the course creator should be aware of intercultural issues they want to draw learners' attention to. Lexical and grammar tasks have to be connected with professional setting, not isolated from the topic of the module.

Moreover, the designed material has to foster the development of the above mentioned global competences required for tourism specialists. Generic and 
intercultural competences may be enhanced in developing all language skills by selecting appropriate tasks containing professional and/or intercultural elements. According to Maican $(2014,277)$ linguistic competence involves teaching such elements as "stress, rhythm, intonation, general grammar related to morphology and syntax, [..] those grammar structures which are appropriate and typical to the formal register". Considering certain types of activities that enhance linguistic competence (ibid, 278) the following activities can be included also in online tasks: word formation, verbs in brackets, multiple matching, finding words, information transfer and multiple choice. Other types of exercises promoting linguistic competence used in the given course are matching tasks finding appropriate synonyms and explanations, paraphrasing, gap fill. Concerning discourse competence, Maican (ibid, 279) offers a wide variety of exercises that develop receptive skills (reading and listening) and productive skills (writing and speaking). The following activities have been used: multiple choice, True/False, blank completion, multiple matching, recreating a message based on notes taken. Speaking activities involve case studies, pair discussions, group discussions, simulations. As it is difficult to test online writing tasks, the created course does not comprise online writing tasks, except for paraphrasing sentences and changing sentence constructions that are connected with using adequate grammar and/or lexical forms. Therefore, it is necessary to pay more attention to developing learners' writing skills during face-to-face stage of the course.

\section{Methodological Framework}

\section{The Context}

This study has been conducted in the Framework of Erasmus + project „Key Skills for European Union Hotel Staff' (Project No. 2014-1-HR01-KA2014007224; project period 2014-2016). Six countries (LV, CR, UK, IT, Sl, RO) are collaborating on the project addressing the specific objectives of Erasmus+ programme in the field of education and training: 1) to improve the level of key competences and skills (namely, employability skills and language competencies), with particular regard to their relevance for the labour market (tourism and hospitality industry) and their contribution to a cohesive society (providing better cultural awareness and increased language competence); 2) to improve language teaching/learning and promote EU's broad linguistic diversity. The project is targeted at developing professional language competence in six EU countries in 12 languages (HR, EN, FR, DE, GR, HU, IT, LV, Sl, RO, RU, ES) and raise hospitality industry employees' intercultural awareness. This paper deals with the second outcome - the course designed for A2/B1 level of 
language competence in 12 languages and B2/C1 English language course to promote tourism students' and employees' language competence and raise their intercultural awareness.

\section{Methodology}

Evaluation research design was applied as it "attempts to determine the value of some initiative [..] and identifies an initiative's consequences as well as opportunities for modification and improvement" (O'Leary, 2010, 138) and it is in line with pragmatism paradigm (Collis \& Hussey, 2009) that has been applied for the whole research project. Evaluation comprises summative and formative evaluation. This paper reflects the stage of formative/process evaluation as it "aims to provide data and information that will aid further development of a particular change initiative" (O'Leary, 2010, 140) and help improving and modifying the course created. "The main objective in formative or process evaluation is assessing an initiative's strengths and weaknesses and asking how the process could be made more efficient and effective" (ibid, 140). Formative evaluation should be conducted from three perspectives - provider, recipient and wider community perspective.

\section{The Sample}

The study comprises four handpicked samples (O'Leary, 2010) created for the research purposes: 1) insiders - the sample of 6 language teachers - project managers involved in the process managing and in all aspects of the course design, 2) insiders - the sample of 14 learners - tourism students and hospitality industry employees piloting the language learning course on mobile application and online learning platform, 3) experts - the sample of 7 hospitality enterprise managers who evaluated the created language learning course, 4) the highly experienced -21 experienced language teachers from 6 countries (CR, IT, LV, $\mathrm{Sl}$, UK) who have evaluated the created language learning course.

\section{The Research Procedure}

The research comprises the following stages: 1) analysis of pedagogical, linguistic and field professional literature on curriculum and course creation, 2) course evaluation from the provider perspective comprising the analysis of self-evaluation reports by the six project managers (document review), 3) course evaluation from the recipient perspective - a focus group discussion involving 14 learners who piloted the course, 4) course evaluation from the wider 
community perspective - a focus group discussion with 7 hospitality industry managers and a survey of 21 language teachers from the 6 partner countries.

The selected methods - document analysis, focus group discussions and a survey were implemented to answer the research question posed according to the evaluation research design theory (ibid, 139): What are the strengths/weaknesses of the course and how could the process be made more efficient/effective for the organisation, the end users and the community?

Focus group discussions were organised in August - September 2015. The face-to-face language teachers' survey was administered in October 2015 applying a questionnaire containing 29 Lickert scale, choice and open questions.

Quantitative data analysis was done applying exploratory data analysis (EDA) and descriptive statistics analysis, qualitative data - applying summarising, categorisation and structuring of meanings using narrative (Saunders et al., 2009).

\section{Findings and Discussion}

The findings of the evaluation research conducted at various levels comprising provider, recipient and community perspective overall pointed to more advantages than disadvantages. However, they also indicated some issues to be improved.

\section{The strengths of the course}

Language teachers (wider community perspective) highly evaluated the curriculum created: twelve teachers $(57 \%)$ evaluated it as very useful, five $(24 \%)$ as useful and four $(19 \%)$ as quite useful. No one had marked it as useless or absolutely useless. Additionally, industry representatives also recognized the topicality of the curriculum and its correspondence to their needs, especially for their employees working in reception and restaurant departments.

The results of the focus group discussion with 14 learners piloting the course provide evaluation from the recipient perspective. All learners agreed that they had received useful information concerning the project and the course. They had evaluated both the information about the mobile application created and its functioning and the FrontDesk program designed as very useful. The layout and design of the application and FrontDesk program can be considered as their strengths as they received a comparatively high evaluation from the recipient perspective: $85 \%$ of learners evaluated the mobile application as very good and good and $93 \%$ of learners evaluated FrontDesk program as very good and good. 
The results of the language teachers' survey support this high evaluation demonstrating the wider community perspective. All teachers expressed their wish to use the learning course for teaching (21), a vast majority would suggest their students to use the course for self-learning (18 teachers) and twelve teachers indicated that they would use the course to develop their language competence in another foreign language which is a good result. This coincides with the results of a focus group discussion with seven hospitality industry managers (wider community perspective) in which they stressed that "both the FrontDesk program and the mobile app created are especially significant for their employees" and they will suggest their staff to use them to improve the English language competence and the competence of other languages as well.

The learners admitted that it was easy to find the necessary information, which may be considered as another strength of the learning course: all learners, except one, told that they could find information easily or quite easily. They also liked the ability to practise short dialogues simulating industry-specific situations. The positive effect of applying such dialogues was also stressed in a previous study on interactive learning platforms by Tehrani and Abdullah (2012).

Another advantage of the learning course created is its multilingual character as it is designed in 12 languages. The majority of learners (13) could not name any other hospitality-based multilingual course available as a mobile application. It has to be explained, that the course structure is similar in all languages as well as a part of the learning material of A2/B1 language course is identical - the vocabulary used, the short dialogues for learning vocabulary and the matching tasks to complete. However, the course designers faced a challenge of which setting to choose - the English version or adapt it in accordance with the end users' needs. Another challenge was creating meaningful grammar and lexical tasks suitable for the target language. Therefore, in many cases the learning material could not be translated from English into other languages, but the tasks had to be created anew observing the same content and pattern. This approach was highly evaluated by language teachers-project managers who represent the provider perspective. The learners (the recipient perspective) also liked this approach as they were able to trace similarities in tasks and when they could not do the task in the target language, they could consult a similar task in their mother tongue or other foreign languages they knew.

The course has been designed using Moodle learning platform which was highly evaluated by all the teachers-managers (the provider perspective) as well as by the language teachers and industry representatives (wider community perspective). Most language teachers (57\%) evaluated it as very useful, $33 \%$ found it useful and $10 \%$ - quite useful. The following quotations from the industry focus group (wider community perspective) confirm the same opinion: 
Ineta Luka. Developing Language Competence for Tourism Students and Employees in a Blended Learning Language Course

I do find the tasks very interesting. If I had such classes at school, I would definitely be more fluent in languages. (Informant $C$, industry focus group)

I like that I can learn in my own speed. As I am very busy and can spare only some time at the weekend for learning, it is good that I can look back at the tasks and see my result and make corrections if needed. I will definitely recommend this course to my reception and restaurant staff. (Informant E, industry focus group)

As the target group consists of a wide range of audience it was necessary to design a learning management system that handles all aspects of the learning process. It should deliver instructional content, identify and assesses individual and organizational learning or training goals, track the progress towards meeting those goals, and collect and present data for supervising the learning process as a whole. Therefore, Moodle platform seemed to be the most suitable for the given needs. Its advantages are free and simple use and as the most popular tool among teachers and students it is well-known in the learning and teaching field. Moodle integrates interactive activities combining simulations, short videos, virtual experiments, games and more, in order to enhance interactive learning based. It offers multiple forms of data retention, communications and course delivery and enables designers to use a whole array of learning models that overcome the classic training routines and obstacles. It features a completely customizable wiki system, forums, resource indexes, and multimedia course models that can be completely reshaped depending on the style and materials the instructor wishes to use (Vöröš \& Petje, 2014).

Regarding the tasks, interactive maps were mentioned as the most creative part of the course enabling learners to learn vocabulary, practice certain grammar constructions, as well as acquire some practical knowledge (for example, connected with skiing resort) and raising learners' intercultural competence (for example, the numerous links on the maps that provide contextspecific and cultural information). This was mentioned in both focus group discussions (learners' discussion and industry representatives' discussion), managers' reports (document analysis) as well as international teachers' survey in which nine teachers $(43 \%)$ gave the highest evaluation, eight teachers $(38 \%)$ recognized them as very useful and four teacher $(19 \%)$ - as quite useful.

\section{The weaknesses of the course}

The focus group discussion with 14 learners piloting the course (recipient perspective) revealed some problems the learners faced. One of the most frequently encountered problems was that certain operating systems did not support the program use, in some versions all the buttons/options were not visible. 
Another weakness marked by the learners was that they found tasks not very creative. Learners would like to have more creative features that could be added to the programs in the future to make the learning process more interesting. This would definitely foster their motivation to learn.

\section{The needs of the organisation}

The needs of the organisation have been defined by evaluating the course from provider perspective based on the document review - managers' reports from all partner institutions. Six partners are involved in the project: Turiba University, Latvia specializing in business, including tourism and hospitality management; Ekonomska šola, Slovenia, a tertiary education institution providing business education; Sapientia University from the Hungarianspeaking part of Romania providing a wide spectrum of study programmes; IPSSA Nino Bergese, a hotel vocational school from Genoa, Italy; TUSDU, a hotel and catering vocational school from Dubrovnik, Croatia; and Primrose Publishing from the UK involved in creating language teaching/learning software and smartphone applications. All the institutions provide also language courses to adults on lifelong learning basis.

The document review (managers' reports) shows the main needs of the organisations as well as the possible benefits for each organisation. A common trend is the requirement to gain B2/C1 English (the first foreign language) language competence level and A2/B1 language level for the second foreign language which differs from organisation to organisation. Another common trend is that in all organisations language studies follow a strict curriculum and are aimed at developing the students' speaking, reading, listening as well as writing skills. Next, all organisations focus on $L S P$. This means that the language learning courses created will be integrated as certain modules in regular curricula, depending on the institution's and the programme's aims and requirements. Therefore, it would be essential to include a guidebook with recommendations on how to integrate the course created in the curricula, if possible, providing some best practice examples. This coincides with the results gained in other research (Richter, McPherson, 2012) stressing the need of definite steps on how to use the on-line course created.

As LSP have dual aims - to develop students' language competence and help acquiring knowledge in their occupation (Laborda, 2011; Maican, 2014; Beacco et al., 2015b), language teaching/learning materials are selected very carefully and they follow the same lines in all the partner institutions. The appropriate language materials are selected according to the curriculum from various sources such as course books, scientific journals, Internet resources etc. This ensures that students are exposed to authentic materials that closely 
correspond to the professional situations that they may face at work. The aim is for students to reach a level of competence enabling them to interact with native speakers in a professional environment without strain for either party. In order to achieve that, socio-linguistic and pragmatic aspects need to be taken into account, as well as the more traditional notions of morphology, syntax and vocabulary. The students must be able to produce brief, simple texts easily and quickly, they need to master the specific vocabulary and phraseology of their area of specialization (hospitality, catering sector, tourism management, business, etc.) and be aware of expectations that may differ from those they are familiar with from contact with their fellow nationals.

This corresponds with the idea expressed by one of the leading ESP practitioners in Language for Tourism Purposes Laborda who confirms that "the most relevant linguistic aspects of LSP are lexical items, language forms, and a topic for conversations while trying to integrate all four skills with authentic texts and audiovisual media. Indeed, authentic materials need to introduce information in shape of accessible input that is not specifically aimed to EFL learners but current specialists on apprentices of certain fields" (Laborda, 2011, 103).

Therefore intercultural competences are very significant. Considering this, intercultural issues could be more stressed; the guidebook designed containing peculiarities in serving different cultures could be supplemented with corresponding tasks on Moodle platform including simulations and case studies.

Currently, in all institutions to ensure the development of intercultural competence, various communicative methods are used for language teaching/learning, such as, pair work, group work, role plays, simulations, case studies. The use of audiovisual material and computers is not only important to make the learning process more interesting and captivating for classes in general; it also provides an opportunity to cater for students' individual learning styles and speed. Modern day aids such as smart phones and tablets are also used whenever possible to gather and analyse information. Students also have to do independent tasks. This is where the blended learning course created will be beneficial as well. The modules designed may be used as supplementary material for regular classes or as home tasks or designated as tasks for individual learning to strengthen the language competences developed during face-to-face learning phase. Therefore, it is essential to have detailed guidelines on how to use the learning platform. Moreover, special training course for language teachers would be an advantage.

The differences were discovered in terms of the course content which differ in accordance with the organisation's profile - tertiary education institution (Latvia, Romania, Slovenia) or vocational education institution (Croatia, Italy). In tertiary education more focus is laid on professional lexis, academic language 
and less focus is on developing students' writing skills, whereas in vocational education institutions, disregarding the fact that the stress is on listening and speaking skills, students' writing skills and knowledge in grammar are developed as well. This again points to the advantage of the created on-line language learning materials which can be flexibly used for various audiences and various purposes.

\section{The needs of the end users}

The above analysis revealed the positive and negative aspects of the courses designed. Both, teachers and students can be considered as potential direct end users of the created course. In the teachers' survey 18 teachers indicated that they would use the FrontDesk program: for teaching language (14 teachers), suggesting students for learning (14 teachers), and improving language skills (12 teachers). 18 teachers indicated that they would use the smart phone apps as well: for teaching language (11 teachers), suggesting students for learning (12 teachers), and improving language skills (11 teachers). All teachers highly evaluated the interactive maps. 20 teachers indicated that they would use them: for teaching language (15 teachers), suggesting students for learning (13 teachers), and improving language skills (12 teachers). They recognise this part as the most creative one, in terms of tasks. This again points to the necessity of elaborating detailed technical guidelines on how to operate the FrontDesk program and mobile application, as well as the interactive maps designed. Examples are necessary, too.

From the perspective of recipients, the learners' focus group interview also pointed to issues that have to be improved. The most important one - it is necessary to find a possibility to run the program on more operating systems. The mobile version of the learning course can be run on Android and IOS software but the learners piloting the program used different phones: Android (11 learners), IOS (1 learner), Symbian (1 learner) and Windows (1 learner). As to computer software, 13 learners used Windows operating system and just one used Apple system.

\section{The needs of the community}

Course evaluation from the perspective of a wider community was done by conducting a focus group discussion with 7 hospitality industry managers and a survey of 21 language teachers from 6 countries. The following quotations from the industry focus group discussion, answers to open questions in language teachers' survey and managers' reports demonstrate the needs of the wider community: 
Ineta Luka. Developing Language Competence for Tourism Students and Employees in a Blended Learning Language Course

Students studying tourism, in particular, must definitely know about hospitality services offered and be able to satisfy guests' needs. So the materials designed will be useful for language learning. (Informant A, industry focus group)

It could become an important support for language simulations and it could help students to develop the language skills required at work. (Informant $B$, industry focus group)

The second part of the course (B2/C1 level English modules) for the hospitality industry are especially suitable for students of faculties and colleges from other university centres, as well as vocational school students (e.g. János Kájoni Vocational School from Miercurea Ciuc) from the region, who are the stakeholders of this project as the curricula of these study courses include topics directly related to the content of the modules. (an English teacher-manager from Romania, the document review)

The language materials developed during the project would be very useful for language learning in various courses implemented by the Department of Languages. The first part of the course (A2/B1 level communicative course in 12 languages) will be very useful for learning mainly German and English but also Italian at the Secondary school for catering in tourism in the region. (an English/German teacher-manager from Slovenia, the document review)

Those directly involved in the hospitality industry, or training students who wish to pursue such a career, will learn a great deal and be made to think. Some of the material will have a much wider appeal than its title suggests and will help participants in their dealings with foreigners well beyond the field of hotels and tourism. (an English teacher from the UK, the teachers' survey)

Both language teachers and industry representatives repeatedly stress the role of languages in serving the customers on daily basis. Moreover, they stress the role of "adequate language skills" and selecting "the right form of expressing themselves" so that their behaviour corresponds to the "business environment" and "satisfies clients of different cultural background". These expressions show the importance of developing intercultural language competence which is a global competence and coincides with at least three of the above-mentioned global competences by Candelier et al. (2012) - managing linguistic and cultural communication in a context of otherness; constructing and broadening of a plural linguistic and cultural repertoire; and competence in recognising the "other" and "otherness". As stressed by an English teacher: "understanding cultural sensitivities will make social intercourse with people from other countries much smoother and prevent the all-too-easy pitfalls caused through ignorance" (an English teacher from the UK, the teachers' survey). This has also been stressed in earlier studies on language teaching/learning in online environment (Candelier et al., 2007; Lund, 2011; Rüschoff, Lund, 2003; etc.). 
This coincides with the needs of organisations and end users concerning the guidebook of intercultural issues, its supplement with more elaborated intercultural tasks, as well as the necessity of having technical and pedagogical guidelines.

The stakeholders especially stressed the significance of speaking and listening skills and the tasks that allow learners to develop those skills. This coincides with the results of the study conducted in Thailand (Prachanant, 2012, 123) which show that speaking is needed for tourism employees to function in their routine work. Listening is rated as the second most used skill. With regard to reading skill, it is ranked as the third most used skill. Compared with the other three skills, writing was viewed as the least important by tourism employees.

To sum up, all industry focus group representatives and all language teachers participating in teachers' survey and/or writing management reports see the usefulness and practical application of the course created both for their institutions and for other institutions (schools, universities, hospitality enterprises) of the city and the region. In terms of this, dissemination is needed so that all relevant stakeholders, including the industry and education institutions, are aware of the opportunity offered for developing learners' language skills and fostering their intercultural competence.

\section{Conclusion}

Tourism is an industry that, compared to other spheres, has experienced the largest economic growth. This has led to the requirement for more staff worldwide. Considering the latest mobility trends and immigration processes in Europe, an urgent need for qualitative, educated staff able to cater for customers' special needs in a culturally acceptable manner, using appropriate language has become crucial. This highlights the necessity of language skills, moreover skills of several foreign languages, among the top employability skills for the hospitality sector. Language has become a tool for operating a business successfully, a crucial tool for participation in socially meaningful activities in multilingual language contexts.

This situation has led to a change in language teaching models in formal and non-formal education. Alongside with traditional language learning, e-learning and blended learning forms are gaining their momentum again. As a result, course designers have responded to this situation and various online teaching/learning materials have been created. The current blended learning course is among them.

The evaluation research conducted in three perspectives - provider, recipient and wider society perspective, revealed the strengths and weaknesses 
of the course, as well as offered suggestions on how to make the process more efficient/effective for the organisation, the end users and the community.

The following strengths have been identified from all the three perspectives (course provider, recipient, community): 1) the curriculum created, which was recognised as corresponding to the stakeholders' needs and flexible for implementation; 2) the layout and design of the mobile application and the FrontDesk program as it was easy to find the information needed; 3) the multilingual character of the course which enables learning the same phrases in several languages and, if needed, finding an adequate phrase and/or expression in another language; 4) the Moodle learning platform which is attractive, modern and flexible, and can be easily adapted for different target groups and various needs; 5) interactive maps which were recognised as the most creative part of the learning course including a myriad of opportunities for their use, from doing simple gap fill tasks to creative intercultural tasks. Two main disadvantages were singled out by the learners (recipient perspective) - technical problems with the operating systems of mobile application and FrontDesk program and not enough creative tasks.

Analysing the needs of the organisation, end users and community, certain suggestions on how to make the course more efficient have been identified:

- The language learning courses created might be used as separate modules in regular curricula, as supplementary material to the existing language teaching aids, as material for students' self-dependent studies. Therefore, detailed pedagogical, technological and intercultural guidelines are required. Such guidelines should be made for the learning program, mobile application, FrontDesk program and the use of interactive maps.

- It is also essential to include a guidebook with recommendations and best practice examples on how to integrate the course designed in regular curricula of the institution.

- Considering the increasing role of intercultural competences for tourism employees, it is advisable to supplement the intercultural guidelines developed with corresponding tasks on the Moodle platform so that learners' could practice when doing language tasks and when facing similar situations in professional setting they would have several scenarios ready for acting.

- Another suggestion is to organise a special training course for language teachers on how to apply the learning platform, the mobile application created and the tasks designed in the study process.

- From the perspective of recipients, it is necessary to find a possibility to run the program in more operating systems than at present as 
learners use different smartphones nowadays and the program should be made such that it could be run on any of them.

To sum up, the conducted formative evaluation research in three perspectives (provider, recipient and community) enabled analysing the strengths and weaknesses of the course and formulate certain recommendations on how to make the course more effective/efficient. All the parties admitted that there are more strengths than weaknesses and that the weaknesses can be eliminated. However, in order to address more audience it is essential to spread the word and disseminate the information about the blended learning course created among tourism industry specialists and education institutions providing tourism curricula.

\section{Acknowledgements}

The current research has been conducted within the Framework of Erasmus+ project „Key Skills for European Union Hotel Staff”, 2014-2016, Project No.: 2014-1-HR01KA2014-007224. The project has been funded with support from the European Commission. This publication reflects the views only of the author, and the Commission cannot be held responsible for any use which may be made of the information contained therein.

\section{References}

Allen, E., Seaman, J., \& Garrett, R. (2007). Blending In: The Extent and Promise of Blended Education in the United States. Needham, MA: Sloan Consortium.

Amemado, D. (2014). Integrating technologies in higher education: the issue of recommended educational features still making headline news. Open Learning: The Journal of Open, Distance and e-Learning, 29 (1), 15-30. DOI: 10.1080/02680513.2014.908700.

Beacco, J. C., Byram, M., Cavalli, M., Coste, D., Cuenat, M. E., Goullier, F., \& Panthier, J. (2015a). Guide for the development and implementation of curricula for plurilingual and intercultural education. Strasbourg: Council of Europe, Language Policy Unit.

Beacco, J. C., Fleming, M., Goullier, F., Thürmann, E., \& Vollmer, H. (2015b). The Language Dimension in All Subjects. A Handbook for Curriculum development and teacher training. Strasbourg: Council of Europe, Language Policy Unit.

Beesley, L. G., \& Davidson, M. (2013). A critical Analysis of Skilled Labor Supply and Demand in the Australian Hospitality Industry. Journal of Quality Assurance in Hospitality \& Tourism, 14 (3), 264-280. DOI: 10.1080/1528008X.2013.802552.

Bueno-Alastuey, M. C., \& López Pérez, M. V. (2014). Evaluation of a blended learning language course: students' perceptions of appropriateness for the development of skills and language areas. Computer Assisted Language Learning, 27 (6), 509-527. DOI: 10.1080/09588221.2013.770037.

Candelier, M. (ed.) (2007). Across Languages and Cultures. Graz: European Centre for Modern Languages.

Candelier, M., de Pietro, J. F., Facciol, R., Lörincz, I., Pascual, X., \& Schröder-Sura, A. (2012). FREPA: A Framework of Reference for Pluralistic Approaches to Languages and Cultures. Competences and resources. Graz: Council of Europe Publishing. 
Ineta Luka. Developing Language Competence for Tourism Students and Employees in a Blended Learning Language Course

CEFR (2001). Common European Framework of Reference for Languages: Learning, Teaching, Assessment. Strasbourg: Language Policy Unit. Retrieved from: http://www.coe.int/t/dg4/linguistic/Source/Framework_EN.pdf.

Collis, J., \& Hussey, R. (2009). Business Research. Basingstoke: Palgrave Macmillian.

Coste, D., \& Cavalli, M. (2015). Education, mobility, otherness. The mediation functions at schools. Strasbourg: Council of Europe, Language Policy Unit.

Frendo, E. (2005). How to Teach Business English. Harlow, Essex: Pearson Education.

Hsu, L. (2013). English as a foreign language learners' perception of mobile assisted language learning: a cross-national study. Computer Assisted Language Learning, 26 (3), $197-$ 213. DOI: $10.1080 / 09588221.2011 .649485$.

Kaya, H. (2015). Blending Technology with Constructivism: Implications for an ELT Classroom. Teaching English with Technology, 15 (1), 3-13.

Kim, H. Y. (2014). Learning opportunities in synchronous computer-mediated communication and face-to-face interaction. Computer Assisted Language Learning, 27 (1), 26-43. DOI: 10.1080/09588221.2012.692386.

King, L., Byrne, I., Djouadj, I., Bianco, J. L., \& Stoicheva, M. (2011). Languages in Europe: Towards 2020. LETTP Consortium.

Labbas, R., \& Shaban, A. E. (2013). Teacher Development in the Digital Age. Teaching English with Technology, 13 (3), 53-64. Retrieved from: http://tewtjournal.org/ issues/past-issue-2013/past-issue-2013-issue-3/.

Laborda, J. G. (2011). Revisiting Materials for Teaching Languages for Specific Purposes. The Southeast Asian Journal of English Language Studies, 17 (1), 102-112.

Learning while Working. (2011). CEDEFOP. Luxembourg: Publications Office of the European Union.

Luka, I. (2015). Enhancing Employability Skills for Tourism and Hospitality Industry Employees in Europe. Journal of Turiba University Acta Prosperitatis, 6, 75-94.

Lund, A. (2011). What's VOLL got to do with it? Sociocultural perspectives on ICT in language learning. In:Fitzpatrick, A., O’Dowd, A. (Eds.). E-VOLLution: Exploring cutting edge applications of networked technologies in Vocationally Oriented Language Learning, 15-27, Graz: European Centre for Modern Languages.

Maican, M. A. (2014). Teaching English to Tourism Students. Bulletin of Transilvania University of Braşow. Series V: Economic Sciences, 7 (56) No.2, 275-283.

Mejia, C., \& Phelan, K. V. (2014). Hospitality Instructors' Preference for Blended Teaching: A Bridge to Full Online Course Delivery? Journal of Teaching in Travel \& Tourism, 14 (4), 343-364. DOI: 10.1080/15313220.2014.955304.

Millar, M., \& Park, S. Y. (2013). Sustainability in Hospitality Education: The Industry's Perspective and Implications for Curriculum. Journal of Hospitality \& Tourism Education, 25 (2), 80-88. DOI: 10.1080/10963758.2013.805090.

Muñoz, J. C., Redecker, C., Vuorikari, R., \& Punie, Y. (2013). Open Education 2030: planning the future of adult learning in Europe. Open Learning, 28 (3), 171-186. DOI: 10.1080/02680513.2013.871199.

O'Leary, Z. (2010). The Essential Guide to Doing Your Research Project. London: SAGE.

Olejarczuk, E. (2014). The E-learning Component of a Blended Learning Course. Teaching English with Technology, 14 (3), 58-68.

Prachanant, N. (2012). Needs Analysis on English Language Use in Tourism Industry. Procedia - Social and Behavioral Sciences, 66, 117-125.

Richter, T., \& McPherson, M. (2012). Open educational resources: education for the world? Distance Education, 33 (2), 201-219. DOI: 10.1080/01587919.2012.692068. 
Rüschoff, B. (2011). Digital media, Web 2.0 and process-oriented language production. In:Fitzpatrick, A., O'Dowd, R. (Eds.),E-VOLLution: Exploring cutting edge applications of networked technologies in Vocationally Oriented Language Learning (pp. 29-42). Strasbourg: Council of Europe Publishing.

Rüschoff, B., \& Lund, A. (2003). New Technologies and Language Learning: theoretical considerations and practical solutions. In: Fitzpatrick, T., Lund, A., Moro, B., Rüschoff, B. (Eds.). Information and Communication Technologies in Vocationally Oriented Language Learning, 13-32, Graz: European Centre for Modern Languages.

Saunders, M., Lewis, P., \& Thornhill, A. (2009). Research Methods for Business Students. Fifth edition. Harlow: Pearson Education Limited.

Scott, D., \& Gössling, S. (2015). What could the next 40 years hold for global tourism? Tourism Recreation Research, 40 (3), 269-285. DOI: 10.1080/02508281.2015.1075739.

Sisson, L. G., \& Adams, A. R. (2013). Essential Hospitality Management Competencies: The Importance of Soft Skills. Journal of Hospitality \& Tourism Education, 25 (3), 131-145. DOI: 10.1080/10963758.2013.826975.

Tehrani, I. A., \& Abdullah, K. I. (2012). Effective Factors in Sustaining Interactive Teacherless Online Communities of Language Learners. Procedia - Social and Behavioral Sciences, 66 (7), 203-216. doi:10.1016/j.sbspro.2012.11.262.

Vöröš, E., \& Petje, D. (2014). Technical report on the choice of Moodle platform. Erasmus+ project „Key Skills for European Union Hotel Staff” (Project No: 2014-1-HR01KA2014-007224). Retrieved from: http://www.language4hotel.eu/index.php/ hierarchical-document-list/croatia/299-technical-report-on-choice-of-platform-3.

Wong, S. C. K., Pang, L. W. L., \& Wong, N. C. (2013). Reflections on Pedagogical Use of Blended Learning in Hospitality Education: A Case Study of Teaching Human Resources Management. Journal of Teaching in Travel \& Tourism, 13 (2), 251-281. DOI: $10.1080 / 15313220.2013 .813329$. 